\section{CHROMOSOME MULTIPLICATION AND REDUCTION IN SOMATIC TISSUES}

\section{THEIR POSSIBLE RELATION TO DIFFERENTIATION, 'REVERSION' AND SEX}

\section{By Prof. C. LEONARD HUSKINS \\ University of Wisconsin}

\begin{abstract}
CY'TOLOGY, which began as a purely descriptive 1 science, bifurcated early in this century into 'karyology' and 'experimental cytology'. By 1925 the karyologists had, as Schrader' points out, assembled a mass of data with far too few unifying concepts. These were furnished in the period 192535 by a closer union with genetics, in which John Belling and C. D. Darlington ${ }^{2}$ played predominant parts, and cytogenetics became the most rapidly developing branch of cytology. When in 1942, as a Guggenheim Fellow, I attempted to write an advanced text-book I began with the assumption, then common to most cytogeneticists, that a synthesis was possible on the basis of generally accepted theories, with only minor modifications and adequate citation of exceptions. I ended with the opinion (cf. ref. 1) that some of the exceptions no longer 'proved the rule' but rather demanded basic revisions of the theories ${ }^{3}$. Of the new research approaches that seemed necessary, one promising line open to the cytologist appeared to lie in the union of cytogeneties with experimental cytology.
\end{abstract}

A beginning was made at McGill University in collaboration with Prof. George Scarth and a joint student, Herbert Stern ${ }^{4,5}$. The War, and at its end Scarth's retirement, deferred developments. A year ago it became possible to begin assembly of a research team at the University of Wisconsin, and a programme was initiated. Two features of it : $(a)$ the determination of chromosome constitution in differentiated tissues, and $(b)$ the experimental production of meiotic ('sexual') divisions in somatic tissues, have reached a stage at which the basic discoveries maty be outlined and their possible significance discussed.

It is now well known to cytologists, though not yet taken into account by most biologists ${ }^{6,7}$, that many animal and plant tissues are characteristically polyploid or polytene (any distinction between these is in part arbitrary, and in any event lacks significance for issues considered herein; both may, presently, be termed polysomaty or endopolyploidy). Geitler, who earlier did much of the best work on animal tissues, in $1940^{\circ}$ recorded polysomaty in thirteen plant species and eleven tissues of these, including infected ones. He concluded, however, that no generalizations could be made regarding its significance since: $(a)$ the data are too scattered, and $(b)$ we know that differentiation can proceed either with increase in cell size, and therefore possible polysomaty, or by increase in cell number with all cells presumably remaining diploid. Since 1940 many new cases of polysomaty have been reported, including the very recent ones in flower-buds and succulent leaves by Geitler's students Lauber ${ }^{9}$ and Jähnl $^{10}$; but no possible rationale for their occurrence has been suggested other than our own ${ }^{11}$. White ${ }^{12}$ sums up the situation in animals as follows: "The whole process of histological differentiation in insects seems to be intimately bound up with this phenomenon of endopolyploidy, each organ and tissue having its own characteristic degree of ploidy, some being entirely composed of one type of cell while others are mosaics of cells with different multiples of the fundamental diploid number. To what extent endopolyploidy occurs outside the Insecta is not known at present, but there are indications that it is fairly widespread in many groups of animals. In the vertebrates conditions are not favourable for counting the chromosomes in somatic resting nuclei, but measurements of nuclear volumes (Jacobj 1925-1935) suggest that in some mammalian tissues several size classes of nuclei exist, and it is possible that these correspond to different degrees of polyploidy."

TABLE 1

\begin{tabular}{|c|c|c|c|c|}
\hline HETEROCF & ATIC BODI & IN RESTING & NUCLEI OF & hoeo discolor \\
\hline$\underset{\text { from tip }}{\mathrm{Mm}}$ & $\begin{array}{l}\text { No. } \\
\text { of nuclei }\end{array}$ & $\begin{array}{l}\text { Mean No. } \\
\text { hetero. }\end{array}$ & $S_{M} D$ & Variance \\
\hline $\begin{array}{l}1 \\
2 \\
3 \\
4 \\
5\end{array}$ & $\begin{array}{r}190 \\
100 \\
99 \\
101 \\
101\end{array}$ & $\begin{array}{l}11 \cdot 1 \\
12 \cdot 1 \\
18 \cdot 1 \\
20 \cdot 6 \\
21 \cdot 3\end{array}$ & $\begin{array}{l}2 \cdot 11 \\
2 \cdot 8 \\
4 \cdot 7 \\
4 \cdot 97 \\
5 \cdot 02\end{array}$ & $\begin{array}{r}4 \cdot 47 \\
7 \cdot 81 \\
22 \cdot 09 \\
24 \cdot 74 \\
25 \cdot 29\end{array}$ \\
\hline
\end{tabular}

Differences of means: $1: 2$, not significant

$$
\begin{aligned}
& 1: 3, \text { not significant } \\
& 1: 4,9 \cdot 5 \pm 4 \cdot 74 P=0 \cdot 045 \\
& 1: 5,10 \cdot 2 \pm 4 \cdot 79 P=0 \cdot 04-0 \cdot 03
\end{aligned}
$$

In 1946 we began, with a possible rationale in mind, an investigation of the extent of polysomaty in plant tissues commonly assumed to be diploid. Roots of Rhoeo were chosen for a first test as these have, in their chromosomes, heterochromatic regions that can be stained in energic ('resting') nuclei. These first studies, with L. Steinitz ${ }^{11}$, indicated that a very large proportion of differentiated cells behind the meristematic region are polysomatic (see Table 1). The test is, however, too indefinite and too subjective, particularly because the heterochromatic regions vary so much in size and fuse so readily. To count the actual chromosomes it is necessary to induce mitosis in cells that ordinarily would probably not divide again. It is, however, then necessary to avoid the induction of polysomaty by the treatment employed. Indole-3-acetic acid in dosages which we consider meet this latter requirement have enabled us to determine that 25-35 (maximum 75 in one root) per cent of the differentiated cells that are induced to divide in Rhoeo roots are polysomatic. (The data of Table 1 indicate that, if all cells could be induced to divide, the proportion seen to be polyploid would be much higher.) We also found both statistical (Table 2) and direct (pairing with chiasma formation) evidence that reduction occurs from polyploidy to diploidy, as Berger ${ }^{13}$ found in Culex, and we saw several haploid nuclei ${ }^{11,14}$.

Repetition of the experiments, by Rhona Leonard, on barley gave similar results. At the same time, it was found by R. E. Duncan and J. G. Ross that the older nuclei of untreated maize endosperm are polytene'11. The total data on polysomaty now make it clear that the axiom that all cells of a plant or animal body have the same chromosome and genic constitution is, quantitatively at least, invalid. In exceptional cases involving 'chromatin diminution' it has long been known that it may be invalid qualitatively, though the presumed absence of genes in heterochromatin complicates this issue. We have under way tests which may possibly help to determine whether, in a more sophisticated sense dependent on a concept of gene structure developed later herein, it lacks general validity. 
TABLE 2

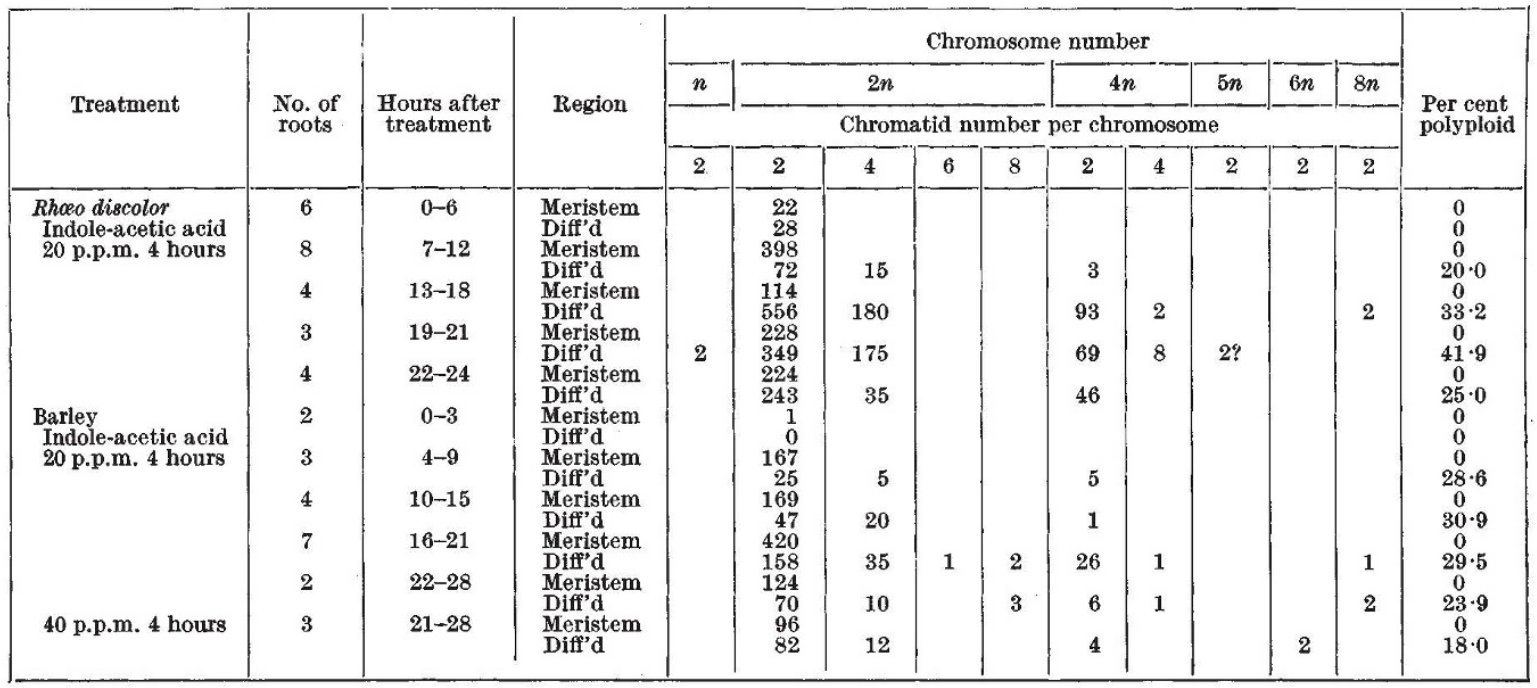

Caspersson $^{15}$ found that at pachytene of meiosis when the paired chromosomes become microscopically four-partite there is a very high nucleic acid content. His conclusion "that nucleic acid plays a role in the synapsis or in the division of the chromonemata or in both" seems basically sound. His further conclusion $^{16}$ that thymonucleic acid has a role in gene reduplication is, however, based on the premature, if not completely inacceptable ${ }^{17}$, identification of chromosome substance with gene and the view that gene reproduction and chromonema splitting coincide. This latter is one of the commonly accepted concepts of cytogenetics that has long seemed to require reconsideration. More than fifteen years ago Nebel, McClintock, Huskins and Smith and others (see ref. 18) showed eytologically that each chromatid in a meiotic tetrad is at least a double, if not a multiple structure, though it behaves as a unit in genetic segregation and usually, if not always as is commonly assumed ${ }^{2}$, in its breakage and mutational response to $\mathrm{X}$-radiation. Nebel ${ }^{19}$ and $\mathrm{I}$ also had what we considered clear evidence of doubleness before pairing. Further, for more than twenty years many of the most cautious cytologists (see ref. 20) have held that the chromosomes of somatic divisions are double at anaphase and therefore contain twice as many strands as genetic evidence leads us to expect. (That the same opinion has also been held on faulty grounds is irrelevant.)

In meristematic cells of onion root-tips treated with sodium ribose nucleate (Swartz Lab. Inc. Sample $S N$ 4509) by M. Kodani ${ }^{21}$ in the course of his studies on the effects of nucleic acids and related compounds on the production of 'lampbrush' chromosomes, I recently found chromosome pairing and reduction divisions, similar in essential respects to those of the germ cells. It should be stressed that, as mentioned above, we had previously found several cases of reductional divisions in differentiated tissues in our indole-3-acetic treated materials, and with Caspersson's conclusions in mind I was looking for them in these slides. Otherwise, for the reasons given below, they would probably have been missed in the initial slides in which they occurred rather infrequently. By using 4 per cent sodium nucleate solution for 5-19 hours Kodani increased the number to several per cent of the total number of dividing cells and made it possible for us to make a detailed analysis.

The possibility that only chance association and distribution of chromosomes was involved has been eliminated by L. Steinitz in experiments on Rhœo roots. In them catenations of several chromosomes, instead of simple pairs, occur as in their germ cells. An 8 per cent solution for six hours has produced this effect in the majority of dividing nuclei.

Some of the pairing in onion roots is with chiasmata, some without. Further tests using structurally modified homologous chromosomes, which will bear on the chiasma-crossing-over relationship, are therefore under way.

From consideration of the cytological literature and our own, unpublished, data and especially since the recent evidence of somatic reduction in cotton ${ }^{22}$, we conclude that our sodium nucleate treatments have only increased the frequency, by abnormal dosage with substances normally present, of a process that occurs naturally but infrequently without treatment. When pairing and reduction-type divisions occur in large numbers, as in our later experiments, they cannot long be missed. If they occur only occasionally, as in normal material, they would usually be missed by the cytologist for two reasons : (a) spindle formation and kinomere orientation on it are abnormal and the general appearance of the first reductional division is that of a cell squashed in preparation; $(b)$ the second division is commonly abortive. When abortive, two nuclei are formed, each with the normal diploid chromosome number (instead of four with the haploid number as when they are not abortive), and in a structurally homozygous organism these two nuclei are indistinguishable, to the cytologist, from the products of a normal mitosis. In a genetically heterozygous organism, however, the result would be seen, as somatic segregation or 'crossing-over' for two homozygous cells, one with the two dominants and the other with the two recessive factors, can result. It is possible that many of the known cases of somatic segregation and/or crossing-over in Drosophila, other animals and plants occur in this way. The demonstration of this mechanism may further have significance for the phenomenon of 'saltation' in fungi lacking known sexual stages, and perhaps in bacteria ${ }^{24}$. 
Sometimes one of the two reduced nuclei divides before the other and before a cell wall is formed between them-as it often does in pollen mother-cell meiosis. This gives sixteen chromosomes at one end of the cell and eight at the other, and, of course, furnishes particularly convincing evidence that a true reduction division and not merely a random segregation of chromosomes has taken place.

The observations render more acceptable the oft. reported cases of chromosome pairing in tumours, particularly since a high nucleic acid content has been found in many tumours. In itself this may be quite distinct from any question of the origin of the tumours. However, in so far as the somatic cell mutation theory of cancer is acceptable, our observa. tions indicate that such 'mutation' may well be somatic segregation in an organism heterozygous for a gene or genes that predispose to tumour susceptibility. The recent work of Greenstein ${ }^{25}$ and Potter et al. ${ }^{26}$ indicates that the changes involved are enzymatic in nature, as are the effects of many gene changes.

Sporadic cases of genome segregation, of which those in strawberries ${ }^{27}$ and oats ${ }^{28}$ are the most striking, also receive one highly plausible rationale from our observations. To get segregation of ancestral genomes from an allopolyploid it is theoretically necessary only to have pairing and segregation of homologous chromosomes in somatic tissue of the germ track prior to a normal meiosis in which there is pairing and segregation of the ancestral homœologues as in the hybrid diploid ancestor. Experiments are therefore being set up in which we shall attempt to abstract ancestral species from polyploids. This may have a bearing on the currently highly contro. versial ${ }^{29}$ problem of 'relic' species.

The simple cytogenetic concept of the chromatid as a unitary string of genes seems to be entirely adequate for crossing-over and the Mendelian transmission of hereditary differences, though not as much so for the data on the production of such differences as is commonly supposed (cf. mosaics). Along with its corollary, the earlier concept of the gene as a unitary organic molecule, it has been a hindrance to thought on the gene as a physiological unit. It is now clear that the gene which acts as a unit in genetic segregation must in some sense be a multiple unit, since its microscopically visible habitat, the chromatid, is at least double. Current concepts of the protein molecule as made up of a number of identical lamellæ give us a model for the gene that seems to fit all present cytological and genetic data and open up the way for new theories of gene action. In particular they permit us to investigate the simplest of all possible hypotheses-and, as Muller ${ }^{30}$ points out, one of the earliest-namely, that the gene acts as a physiological unit just as it does in inheritance by reproducing itself, or, more specifically, its platelets. (By using the term 'gene' to refer, for the present, either to a platelet or a multiplicity of platelets we are adding only one new concept to the several already subsumed under that term.) The axiom of chromosome and genic identity of all cells in a plant and animal body, which is now shown to be an incomplete and perhaps misleading concept, has previously prevented serious consideration of this hypothesis-see Wright ${ }^{31}$, in which he points out that on the accepted theories of gene structure and identity of all cells a gene could reproduce itself only once between each nuclear division. This limitation as applied to platelets no longer holds. The discovery of nuclei with chromosome, and especially chromatid, numbers other than an exponential power of two (Table 2) may be of very great, though indirect, significance in this connexion. The next and most difficult step in the testing of this hypothesis is to determine whether all parts of a chromosome and all genes reproduce at the same rate. There is already much evidence that heterochromatin and 'differential regions' do not-included in this evidence is that of R. E. Duncan ${ }^{32}$, who has further unpublished data that fall in line.

The concept we currently favour is that the gene, and its visible manifestation or habitat the chromatid segment or 'chromomere', must continuously be reproducing itself in all living tissues by the production of new platelets. Failure to do so would be one means of 'chromatin diminution'. Possibly this is what Goldschmidt has in mind ${ }^{33}$ when he remarks that it occurs only in organisms with a limited cellular reproduction.

Wright ${ }^{31}$ has pointed out that a mutation in one of the postulated lamellæ of a gene may (conceivably by "the same mechanism as involved in the duplica. tion process") be restored rapidly or spread through them all. Gulick ${ }^{17}$ considers this highly probable and adds that since genetic stability is founded on stability of chromosome organisation, natural selection will be expected to have ensured that restoration occurs in the majority of cases. The relative rarity of mosaicism is therefore expected even on the lamellar hypothesis of gene structure, while its occasional occurrence is thereby readily explained.

It may well be, of course, that polysomaty is not so direct an indication of the mode of gene action as the present hypothesis postulates. That it has some relation to the physiological activity of the gene now seems self-evident. Since the above data on higher plants, insects, and mammals were evaluated there have come to hand the papers of Subramaniam ${ }^{34}$ claiming a relationship of "endopolyploidy" to enzymatic activity in yeasts and indicating its probable significance in the macronucleus of ciliates. It begins to look as if continued mitoses are essential to the preservation of diploidy. The significance of this possibility for theories on the isolation of the germ plasm are obvious.

To summarize the argument from the data on somatic reduction: A combination of four steps, each of which is now firmly established as occurring normally (and with higher frequency in experiments with normally occurring environmental substances or influences in unusual dosages but within a range consistent with viability), is sufficient to account, theoretically at least, for all the basic cytogenetic and evolutionary features of sex. They are, to state a hypothetical case for the purpose of exposition : (1) endomitosis (as an alternative to the nuclear fusion usually proposed) in a haploid organism giving rise to diploid tissue; (2) complementary mutations (it is, for the moment, irrelevant whether genic or chromosomal) in the two sets of chromosomes which render either one individually less efficient than the combination of both ; (3) somatic reduction, with or without crossing-over; (4) fusion of reduced nuclei (or, in dikaryonts, of cells). These give us the cytogenetic essentials of sex without sexes or sexuality. All successive developments of sexuality may be viewed as adaptive mechanisms facilitating the orderly sequence of the reduction and fusion. On this simple view 'incompatibility' reactions are the evolutionary forerunner of ordinary sexuality, though reversion can, obviously, occur. The number of 
complementary heterothallic forms is unlimited; the number of true sexes is limited to two because there must be very close association of many adaptive features. All the above issues have, of course, been considered by many writers and especially clearly by Darlington ${ }^{36}$. Beadle's ${ }^{35}$ scheme has similarities but also fundamental differences; he, further, accepts Darlington's conclusion that nuclear fusion and meiosis must have arisen simultaneously, which is not necessary in the above scheme. Our contribution, regardless of hypothetical significance, is the experimental production of the third, and previously most inexplicable, step, and from Stern's ${ }^{5}$ work a suggested experimental technique for the production of fusion within a single organism. Our scheme has one advantage over others in that somatic reduction may in some cases (cf. ref. 22) have immediate selective value for the tissue involved and not only for the progeny ${ }^{36}$.

To conclude, the occurrence of polysomaty and polyteny in differentiated tissues and of somatic reduction divisions equivalent to both complete and incomplete meiosis are established, and also the optical doubleness (if not the multi-strandedness) of the chromatid which is nevertheless the unit of Mendelian segregation. The speculations on the possible significance of the data are predominantly of the nature of working hypotheses which can, though to very varying degrees, be tested. Their validity, or lack of it, at this stage is therefore immaterial to their possible usefulness. Further obvious speculations on issues such as the relationship of the postulated platelets to 'plasmagenes', etc., are not indulged in since we see at present no way for the cytogeneticist to test them.

It must be emphasized that though I accept full and sole responsibility for all statements above, the work is that of a team in which I have the collaboration of three senior and seven junior associates. In the detailed publications to follow, authorship and accrediting will indicate the particular contributions of each in so far as this is possible with a team the members of which, to end on a cytological analogy, are, like cells, individual units at the level of differentiation, that is, in their special studies, and sub-units at the integrative level, that is, in the general programme. Financial support is provided by the Wisconsin Alumni Research Foundation and, through the award of one fellowship, by the National Research Council, Committee on Growth.

\footnotetext{
${ }^{1}$ Schrader, F., Presidential Address, Section F, Amer, Assoc. Adv. Sci.

(1947).
"Darlington, C. D., "Recent Advances in Cytology" (Churchill, 1937).

'Huskins, C. L., J. Hered., 35, 81 (1944); 86, 43 (1946).

'Stern, H., Trans. Roy. Soc. Canada, 40, 141 (1946).

'Stern, H., J. Hered., 37, 46 (1946).

- Glaser, O., Trans. New York Acad. Sei., 4, 5 (1941).

? Sinnott, E. W., and Bloch, R., Amer. J. Bot., 33, 587 (1946).

${ }^{8}$ Geitler, L., Ber. Deutsch Bot. Ges., 58, 131 (1940).

- Lauber, Henriette, Ost. Bot. Z., 94, 30 (1947).

${ }^{10}$ Jăhnl, Gertrud, Chromosoma, 3, 48 (1947).

${ }^{11}$ Huskins, C. L., Proc. Roy. Soc. Canada (1947).

12 White, M. J. D., "Animal Cytology and Evolution" (Cambridge Univ. Press, 1945).

1s Berger, C. A., Pub. Carnegie Inst., Washington, 496 (1938).

" Huskins, C. L. (Discussion Cold Spring Harbor Symposium, June 1947 , in the press).

${ }^{15}$ Caspersson, T., Arch. Exp. Zellf., 22, 655 (1939).

14 Caspersson, T., Chromosoma, 1, 147 (1939).

${ }^{17}$ Gulick, Addison, Bot. Rev., 7, 433 (1941) (and personal conversation).

${ }^{13}$ Sharp, L. W., "Introduction to Cytology" (McGraw-Hill Book Co., 1934).

${ }^{19} \mathrm{Nebel,} \mathrm{B.} \mathrm{R.,} \mathrm{Z.} \mathrm{Zellf.} \mathrm{Mikr.} \mathrm{Anat.,} \mathrm{16,} 251$ (1932).

20 Kaufmann, B. P., Amer. J. Bot., 13, 59 (1926); Bot. Rev., in the press.
}

${ }^{21}$ Kodani, M. (in the press).

${ }^{28}$ Brown, Meta A., Amer. J. Bot., 34, 384 (1947).

${ }^{28}$ Stern, Curt, Genetics, 21, 625 (1936).

${ }^{24}$ Lederberg, J., and Tatum, E. L., Nature, 158, 558 (1946).

${ }^{25}$ Greenstein, J. R., "Biochemistry of Cancer" (Acad. Press. N.Y., 1947).

${ }^{26}$ Potter, V. R., IVth Int. Symp. on Cancer (in the press, 1947).

${ }^{27}$ East, E. M., Genetics, 19, 167 (1934).

${ }^{28}$ Nishiyama, I., Cytologia, 5, 146 (1933).

${ }^{20}$ Rousseau, J., Ecol. Soc. America, Amer. Assoc. Adv. Scl. meeting (1947).

${ }^{30}$ Muller, H. J., Proc. Roy. Soc., B, 134, 1 (1947).

si Wright, Sewall, Amer. Nat., 79, 289 (1945).

${ }^{32}$ Duncan, R. E., Amer. J. Bot., 32, 506 (1945).

${ }^{33}$ Goldschmidt, R., and Teh Ping Lin, Science, 105, 619 (1947).

34 Subramaniam, M. K., Curr. Sci., 16, 157, 228 (1947).

${ }^{85}$ Beadle, G. W., and Coonradt, Verna L., Genetic8, 29, 291 (1944).

"Darlington, C. D." “The Evolution of Genetic Systems" (Cambridge Univ. Press, 1939)

\section{THEORY OF ELECTROKINETIC EFFECTS}

\section{By F. BOOTH \\ H. H. Wills Physical Laboratory, University of Bristol}

$T$

THE purpose of this article is to summarize the present position of the theory of electrokinetic phenomena and to present certain new mathematical results I have obtained, the details of which will be published later.

In electrokinetic phenomena we are concerned always with the electrical double layer at the boundary between an electrolyte and a solid. Two types of theoretical problem arise in considering the effects of this double layer, depending upon whether equilibrium, or non-equilibrium irreversible conditions (in the thermodynamic sense), prevail. An example of the first type of problem is the determination of the mechanical force between two solid particles at rest immersed in an electrolyte also at rest. This problem, of fundamental importance in colloid chemistry, has been solved successfully by Verwey ${ }^{1}$ after many abortive attempts by other workers. The second type constitutes the subject matter of this article; here dynamic rather than static conditions prevail, and we have to determine various consequences of the effect of the double layer on the flow of an electrolyte past a solid surface. These electrokinetic effects have, apart from their intrinsic interest, important industrial and biological applications ${ }^{2}$. The main electrokinetic phenomena are:

1. Cataphoresis or electrophoresis; this is the motion of the particles in a suspension when an electric field is applied (Reuss, 1808).

2. Electro-osmosis; this is the flow of a liquid through a capillary when an electric field is applied parallel to its axis. Closely related is the effect known as electro-osmotic pressure; if the flow through a horizontal capillary is prevented, a difference of pressure develops between the ends when the field is applied (R. Porret, 1816).

3. Streaming potentials; the potential set up between the ends of a capillary when an electrolyte is forced through it (Quincke, 1859).

4. Sedimentation potentials. A suspension of particles, if allowed to settle, sets up a vertical electric field (Dorn, 1878). A very similar effect is the difference of potential which develops between the nodes and antinodes set up by stationary sound waves in a suspension (see, for example, Hermans ${ }^{8}$ ). 